\title{
The national financial adjustment policy and the equalisation of health levels among prefectures
}

\author{
T Takano, K Nakamura
}

\begin{abstract}
Study objectives-The objectives of this study were to examine (1) trends concerning financial assistance from the national government to local governments, (2) trends regarding death rates and life expectancies among prefectures, and (3) the effect of the national financial adjustment policy in equalising both the revenues of local governments and variations in the health levels among prefectures in terms of death rates and life expectancies. Design-The study analysed prefectural income, the amount of national taxes collected, financial assistance from the national government to local governments, and age adjusted death rates and life expectancies of all of the prefectures in Japan during the period from 1965 through 1995.
\end{abstract}

Main results-(1) Under the financial adjustment policy, financial assistance from the national government to the local governments, which consists of the sum of the local allocation tax and treasury disbursements, increased from 1831 billion yen in 1965 to 31116 billion yen in 1995. (2) During the same period, the age adjusted death rate per 100000 people decreased from 1168.9 (1965) to 545.3 (1995). The range of variation in the age adjusted death rate among prefectures diminished as the coefficient of variation of the death rate declined from 0.060 in 1965 to 0.043 in 1995. (3) There was a significant statistical correlation between higher prefectural incomes and lower mortality rates during from 1965 until 1975 ( $p<0.05)$, whereas this correlation was indistinct in the 1980 s and has not been observed since 1990. (4) The relative health level of Tokyo has declined in terms of its ranking among all the prefectures with regard to life expectancy, from being the best in 1965 to below average in 1995 . Conclusions-The national financial adjustment policy to balance the revenues of local governments has increased the health levels of rural prefectures. It is probable that the policy reduced the disparity in death rates and life expectancies among prefectures throughout the country. However, the policy has precluded the nation's capital city from applying its economic resources as local government expenditures to deal with the megacity issues affecting health. (F Epidemiol Community Health 2001;55:748-754)
The national system for adjusting finances among the local prefectural governments has been regarded as functioning well in Japan. ${ }^{1}$ The system is necessary to redress imbalances in the revenues of local governments of the nation's 47 prefectures, in order to keep public services above the minimum level all across the country to ensure that development is balanced all across the nation.

The aforementioned financial adjustment is achieved mainly through the local allocation tax (local grant tax) and treasury disbursements (grants to local governments). ${ }^{2}$ With regard to the local allocation tax (local grant tax), this system allocates to the local governments a certain percentage of the taxes collected by the national government, in order to equalise the financial resources that are available to individual local governments to implement necessary public services. ${ }^{3}$ The local allocation tax is given to individual local governments according to the amount, as calculated by the national government, of a local government's revenue shortage. Treasury disbursements (grants to local governments) consist of a variety of grants from the national government to local governments for specific purposes, including public investment to develop social overhead capital, social security, and education. ${ }^{12}$ Such grants are disbursed when a local government needs financial assistance from outside to implement a local project that is considered to benefit the population.

It is widely recognised that the determinants of health are diverse, including healthcare; welfare; education; housing; the infrastructure, such as roads, water supply, and sewage; and the level of development of the local economy. ${ }^{4-7}$ A greater proportion of public services relating to these health determinants is provided by local governments than by the central government. ${ }^{1}$ The public sector is responsible for a greater share of expenditures on health supporting services at the local level than the private sector is. ${ }^{8}$ Accordingly, local governments assume a large share of the responsibility for developing and maintaining appropriate conditions regarding the determinants of health in a city, and for providing health supportive services therein. The availability of revenue to meet these requirements affects the ability of a local government to implement programmes concerning the development and maintenance of relevant infrastructures and services.

Since 1965, health levels, represented by life expectancies, in the rural prefectures has increased sharply, while the health level of the 
nation's capital city, Tokyo has showed a moderate change. ${ }^{9}$ Rural prefectures refer to prefectures other than Tokyo, Osaka, and Aichi. The health level of Tokyo, which once was one of the highest in the country, has declined in rank since $1980 .{ }^{10}$ And in 1990, the health level in the east part of Tokyo was distinctively lower than the national average. ${ }^{11}$ An interesting query is why Tokyo's health level ranking has declined despite the city's economic productivity.

We examined the national adjustment system in terms of its effects, during the 1965-1995 period, both on redressing imbalances in local revenues and on health level trends, the second as measured in terms of the death rates and life expectancies of prefectures. To evaluate prefectural health levels, we examined absolute values, relative levels, and variances of indicators. The objective of this study was to examine (1) trends concerning financial assistance from the national government to local governments, (2) trends concerning death rates and life expectancies among prefectures, and (3) the effect of the national financial adjustment policy in equalising both the revenues of local governments and variations in the health levels among the prefectures in terms of death rates and life expectancies.

\section{Methods}

TRENDS CONCERNING ECONOMIC/FINANCIAL INDICATORS

The following indicators by prefectures, including the Tokyo Metropolis, for five year intervals from 1965 through 1995 were calculated by using reports concerning prefectural accounts, national taxes, local finance records, and census data. ${ }^{12-16}$ We analysed the trends concerning the sums of all of the economic/ financial indicators for both all of the prefectures and each individual prefecture.

Prefectural income: prefectural income, similar in nature to national income, was defined as the total amount of income generated by businesses, inhabitants, and other entities that reside or exist in a prefecture. The amount was calculated in accordance with the System of National Accounts instituted by the United Nations. ${ }^{12}$ Per capita prefectural incomes were calculated using population data reported by census. ${ }^{13}$

Gross domestic expenditures: data of the national gross domestic expenditure on the annual report of national accounts of Japan were complied from the annual report of national accounts of Japan. ${ }^{14}$ These data were regarded as the equivalent of GDP based on the United Nation's 1968 System of National Accounts.

National taxes collected: among the items relating to national taxes, the total amounts of the following taxes collected by prefectures were calculated: income tax (earnings tax), corporation tax (enterprise tax), consumption tax, inheritance tax, liquor tax, stamp tax, oil tax, and tobacco tax. ${ }^{15}$

Financial assistance from the national government to local governments: financial assistance from the national government to local governments takes the forms of the local allocation tax and national treasury disbursements. Individual amounts and total amounts by prefectures were calculated for the following.

(A) Local allocation tax: the sum of the amount of tax given to each prefectural government from the national government and the amounts of that tax given from the national government to municipal governments in the same prefecture was used as the total amount of the local allocation tax given from the national government to that prefecture. ${ }^{16}$

(B) Treasury disbursements: treasury disbursements from the national government to local governments include shared payments for compulsory education; public works; unemployment insurance programmes; disaster relief; subsidies and grants to carry out various projects having specific purposes; and commissions to carry out certain administrative duties of the national government that have been entrusted to local governments. ${ }^{1}$ The sum of the amount of treasury disbursements paid to each prefectural government and the amounts of those given to municipal governments in the same prefecture was used as the total amount of treasury disbursements from the national government to that prefecture. ${ }^{16}$

Prefectural contribution: because the financial assistance comes from national revenues, of which $75.3 \%$ consists of taxes paid to the national government (as of 1998), the above mentioned financial assistance can be characterised as a mechanism to reallocate income across the nation. On this basis, we defined a prefectural contribution as the net amount of money transferred from a prefecture to the national coffers.

A prefectural contribution was calculated as follows:

Prefectural contribution $=$ (total amount of national taxes collected in a prefecture) $-($ (local allocation taxes to that prefecture and to municipalities in that prefecture) + (treasury disbursements to the prefecture and its municipalities))

A prefectural contribution excluding the corporation tax also was calculated, as follows: Prefectural contribution without corporation tax $=$ (total amount of national taxes, not including the corporation tax, collected in a prefecture $)-(($ local allocation taxes to that prefecture and to municipalities in that prefecture) + (treasury disbursements to the prefecture and its municipalities))

If, for example, a prefectural contribution was a positive amount, it can be said that the prefecture was contributing to the welfare of other prefectures. In contrast, a negative amount would mean that the prefecture is being supported by other prefectures. We also calculated the per capita amounts of prefectural contributions and prefectural contributions excluding the corporation tax.

\section{TRENDS CONCERNING HEALTH INDICATORS}

The following statistics were collected and formulated by prefectures, including the Tokyo Metropolis, for five year intervals from 1965 to 
1995. The relative positions of the health level of Tokyo residents were examined by using the following: Tokyo residents' rank, among all the 47 prefectures in Japan, of life expectancy at birth; absolute value of the deviation from the prefectural average of the age adjusted death rates of Tokyo residents; and the standardised value of the deviation of the age adjusted death rates of Tokyo residents. Okinawa Prefecture was not included in this analysis for 1965 and 1970 because it was under the Ryukyu government at that time; Hyogo Prefecture was not included in 1995 statistics because of its increased death rate after the Hanshin-Awaji earthquake that occurred in that year.

Life expectancy at birth: life expectancy at birth $\left(e_{0}\right)$ represents the number of years that a newborn baby is expected to live, based on the assumption that the death rates by age of that year will continue forever. This is shown in the life tables produced at five year intervals. ${ }^{9}$ The life tables were calculated by assuming that the death rates by age will continue forever, and that the surviving portion of the people born in a given year will decrease annually according to the death rates for each individual age. Death rate by age $\left({ }_{n} q_{x}\right)$ : probability that a person of age $x$ will die before reaching age $x+n$; number of survivors $\left(l_{x}\right)$ : number of surviving people out of 100000 births, according to their expected age of death according to the life table's assumptions; steady population $\left({ }_{n} L_{x}\right)$ : the population of the age $x$ and above and under the age $(x+n)$, based on the assumption that 100000 babies will be born every year and that the death rates by age will continue forever; steady population over a specified age $\left(T_{x}\right)$ : the sum of the steady population of the age $x$ and above; life expectancy at a specified age $x\left(e_{x}\right)$ : number of expected years of living for a person of age $x$, and calculated as follows: $e_{x}=\left(T_{x} / l_{x}\right)$. The life expectancy at birth represents the overall health level of a community independent of the demographic structure of the community and in different years over time.

Age adjusted death rate: the age adjusted death rates per 100000 people for men, women, and both genders by prefecture were calculated by using the death rates of the individual age categories of the concerned population and the number of people by age categories in a model population, based on a demographic structure in 1985 , using the following equation. ${ }^{17}$

DRx: death rate of age category $x$ of an observed population

Px: population of age category $x$ of a model population

$A D R$ (age adjusted death rate)

$=\Sigma D R x \times P x) / \Sigma P x$

These statistics enable one to assume the expected number of deaths if the structure of the population is the same and excludes any possible bias relating to the difference of demographic structures among the concerned populations.

Reduction percentage of the age adjusted death rate by 10 years: we also calculated, by prefecture, the reduction percentage of the age adjusted death rate during the previous 10 years divided by the value at the beginning of the 10 year period. This statistic shows the relative size of the reduction regardless of the absolute value of the death rate, and it indicates comparable figures over time.

RELATION AMONG ECONOMIC AND HEALTH LEVEL INDICATORS

We calculated Pearson correlation coefficients between prefectural income and prefectural contribution for each year at five year intervals from 1965 to 1995 .

We then analysed the relation between economic indicators-prefectural income and prefectural contribution-and health level indicators. Pearson correlation coefficients between per capita prefectural income and the age adjusted death rates, and that between per capita prefectural contribution and the age adjusted death rates were calculated for each year at five year intervals from 1965 to 1995 .

\section{Results}

Table 1 shows trends concerning the prefectural income; gross domestic expenditure; the total amount of national taxes collected; the total amount of financial assistance from the national government to local governments, including local allocation taxes given to local governments, and annual treasury disbursements at five year intervals from 1965 through 1995.

In 1995, people and business in Tokyo paid 16240 billion yen (US $\$ 172.8$ billion at an exchange rate of $93.97 \mathrm{yen} / \$$ ) to the national government, and this amounted to $30.9 \%$ of the total national tax collected in that year. The amount and the percentage collected were the highest in 1990, at 20356 billion yen and $33.7 \%$, respectively, during the so called bubble economy period.

The per capita amount of prefectural income in 1965 was 268 thousand yen, and in 1995 it was 3118 thousand yen (table 1). The per capita amount of the local allocation tax given to the prefectural governments varied from 0 yen, the amount received by the Tokyo Metropolitan Government, to 245 thousand yen, the amount received by the Shimane Prefectural government in 1995. The Tokyo Metropolitan Government has never been offered the local allocation tax, and since 1993 it has been the only prefectural government to which such tax money has never been offered. Aichi, Kanagawa, and Osaka Prefectures had not been allocated any such tax money before 1993 .

In 1965 , the per capita amount of prefectural financial contributions to the national government, which is the net amount of money transferred from a prefecture to the national coffers, varied from the 70 thousand yen of Tokyo to the -34 thousand yen of Shimane Prefecture. The second largest per capita prefectural contribution in 1965 was by Kanagawa Prefecture, 47 thousand yen. In 1995, such contributions varied from the 1328 thousand yen of Tokyo to the -467 thousand yen of Shimane. This means that, through the national adjustment system of public finance, in 1995 the people of Tokyo contributed 1328 thousand yen per 
Table 1 Trends concerning the total amount of prefectural financial indicators of all the prefectures

\begin{tabular}{|c|c|c|c|c|c|c|c|}
\hline & \multicolumn{7}{|l|}{ Year } \\
\hline & 1965 & 1970 & 1975 & 1980 & 1985 & 1990 & 1995 \\
\hline Total amount of prefectural income ${ }^{\star}$ of all the prefectures (billion yen) & 26290 & 59502 & 124412 & 199225 & 263859 & 363296 & 391524 \\
\hline Per capita amount of prefectural income (thousand yen) & 268 & 574 & 1111 & 1702 & 2180 & 2939 & 3118 \\
\hline Gross domestic expendituref (billion yen) & 32800 & 73345 & 148327 & 240176 & 320419 & 430040 & 483220 \\
\hline Total amount of national taxes collected $\ddagger$ (billion yen) & 2787 & 6906 & 13479 & 25740 & 36887 & 60471 & 52575 \\
\hline $\begin{array}{l}\text { Total amount of financial assistance from the national government to local } \\
\text { governments }\{\text { (billion yen) }\end{array}$ & & & & & & & \\
\hline $\begin{array}{l}\text { governments } \$ \text { (billion yen) } \\
\text { Total amount of local allocation taxes given to local governments } \| \text { (billion yen) }\end{array}$ & $\begin{array}{r}1831 \\
743\end{array}$ & $\begin{array}{l}3879 \\
1798\end{array}$ & $\begin{array}{r}10292 \\
4471\end{array}$ & $\begin{array}{r}18619 \\
8114\end{array}$ & $\begin{array}{r}19868 \\
9450\end{array}$ & $\begin{array}{l}24957 \\
14328\end{array}$ & $\begin{array}{l}31116 \\
16153\end{array}$ \\
\hline Total amount of annual treasury disbursements (billion yen) & 1088 & 2081 & 5821 & 10505 & 10418 & 10629 & 14963 \\
\hline
\end{tabular}

*Income generated by residents, businesses, and other entities that reside or exist in a prefecture. †Equivalent of gross domestic products based on the System of National Account (1968 SNA). ¥Income tax, cooperation tax, and other national taxes collected. §Total amount of money transferred from the national coffers to prefectures (sum of $\|$ and $\uparrow$ ). $\|$ Local allocation tax money given to a each local government from the national government. $\uparrow$ Subsidies to the local governments from the national government.

capita toward the welfare of people in other prefectures, and that the people of Shimane were supported by the people of other prefectures in the amount of 467 thousand yen per capita. The second largest per capita prefectural contribution was made by Osaka, at 545.3 thousand yen. Even in terms of the per capita amount of prefectural contributions excluding the corporation tax, Tokyo made distinctively large contributions from 1965 to 1995. In 1965, the amount of Tokyo's contribution excluding the corporation tax was 24 thousand yen, and in 1995 it was 460 thousand yen; the second largest contributions were the 11 thousand yen of Osaka in 1965 and the 131 thousand yen of Osaka in 1995.

Table 2 presents indicators that show the relative health level of Tokyo for the 1965-1995 period: the ranking of the life expectancy at birth of Tokyo's male and female populations, the deviation of the age adjusted death rate of Tokyo residents from the average for all prefectures, the standardised age adjusted death rate of Tokyo residents, the reduction percentage of the age adjusted death rate by 10 years for both the Japanese and Tokyo populations, and the standardised reduction percentage of the age adjusted death rate by 10 years for Tokyo residents.

The life expectancy at birth of the male and female Japanese populations increased from 67.74 in 1965 to 76.70 in 1995 , and from 72.92 in 1965 to 83.22 in 1995 , respectively. Those of Tokyo also increased, from 69.84 in 1965 to 76.91 in 1995, and from 74.70 in 1965 to 83.12 in 1995 , respectively. The life expectancy at birth of Tokyo's male population was ranked first from 1965 through 1975, but it has decreased since then. Similarly, the life expectancy at birth of Tokyo's female population was ranked first in 1965, but it then fell, dropping to $33 \mathrm{rd}$ of 47 prefectures in 1995.

The average age adjusted death rate of all prefectures decreased from 1168.9 per 100000 people in 1965 to 545.3 per 100000 in 1995. Regarding the variation of the death rate among prefectures, the coefficient of variation of the age adjusted death rate was 0.060 in 1965 and 0.043 in 1995 . This indicates that the variation among the prefectures diminished over time. Tokyo's death rate has been significantly lower than the prefectural average in 1965, but in 1995 it was slightly higher than the average, and its reduction percentage declined after 1985. Tokyo's reduction percentage of the age adjusted death rate by 10 years has been consistently smaller than that of Japanese average. Tokyo's deviation from the national average was statistically significant in 1990 and 1995.

The correlation coefficient between the per capita prefectural income and per capita financial contribution by prefectures were between 0.80 and 0.94 from 1965 through 1995 ( $p<$ $0.001)$.

Table 3 shows the correlation between the age adjusted death rate and per capita prefectural income or per capita prefectural contributions from 1965 to 1995 . The negative correlation between the age adjusted death rate and prefectural income was statistically significant from 1965 to 1975; a negative, but statistically significant, correlation existed in 1980 and 1985; and no clearly distinct correlation existed

Table 2 Relative decline of the health level of Tokyo

\begin{tabular}{|c|c|c|c|c|c|c|c|c|}
\hline & & \multicolumn{7}{|l|}{ Year } \\
\hline & & 1965 & 1970 & 1975 & 1980 & 1985 & 1990 & 1995 \\
\hline Ranking of the life expectancy at birth, male, Tokyo & rank & 1 & 1 & 1 & 4 & 5 & 14 & 20 \\
\hline Ranking of the life expectancy at birth, female, Tokyo & rank & 1 & 3 & 2 & 7 & 11 & 27 & 33 \\
\hline \multicolumn{9}{|l|}{ Deviation of the age adjusted death rate ${ }^{\star}$ of Tokyo } \\
\hline residents from the average for all prefectures & per 100000 population & -144.3 & -96.0 & -76.0 & -53.2 & -31.2 & -4.3 & 2.1 \\
\hline Standardised age adjusted death rate $\nmid$ of Tokyo residents & & -1.979 & -1.76 & -2.039 & -1.69 व & -1.11 & -0.19 & 0.09 \\
\hline Reduction percentage of the age adjusted death rate by & per 10 years per 100000 & & & & & & & \\
\hline 10 years $\ddagger$ for the Japanese population & population & & & 25.25 & 27.15 & 25.37 & 22.94 & 16.09 \\
\hline Reduction percentage of the age adjusted death rate by & per 10 years per 100000 & & & & & & & \\
\hline 10 years $\ddagger$ for the Tokyo residents & population & & & 22.28 & 25.47 & 22.22 & 17.79 & 11.62 \\
\hline $\begin{array}{l}\text { Standardised reduction percentage of the age adjusted } \\
\text { death rate by } 10 \text { years } \$ \text { for the Tokyo residents }\end{array}$ & & & & -1.08 & -0.72 & -1.22 & -2.229 & $-1.86 \uparrow$ \\
\hline
\end{tabular}

^Age adjusted dearth rate calculated based on a 1985 model population. $\dagger$ Standardised value of $\star$. $\ddagger$ Reduction of age adjusted death rate during the previous 10 years divided by the value at the beginning of this 10 year period. (Standardised value of $\ddagger$. $q$ The indicated value is out of mean $\pm 1.67 \times$ SD. Okinawa Prefecture was not included in the analysis because the area was not a part of Japan in 1965 and 1970 . Hyogo Prefecture was not included in the analysis of year 1995 because of the earthquake occurred in that year. 
Table 3 Correlation between the age adjusted death rate and prefectural financial indicators

\begin{tabular}{|c|c|c|c|c|c|c|c|}
\hline & \multicolumn{7}{|l|}{ Year } \\
\hline & 1965 & 1970 & 1975 & 1980 & 1985 & 1990 & 1995 \\
\hline $\begin{array}{l}\text { Correlation coefficient between death rate } \nmid \text { and } \\
\text { per capita prefectural income } \neq\end{array}$ & $-0.398^{\star}$ & $-0.555^{\star}$ & $-0.482^{\star}$ & -0.353 & -0.240 & -0.120 & -0.158 \\
\hline $\begin{array}{l}\text { Correlation coefficient between death rate } \dagger \text { and } \\
\text { per capita prefectural contributions } \\
end{array}$ & $-0.467^{\star}$ & $-0.560^{\star}$ & $-0.471^{\star}$ & -0.352 & -0.151 & -0.012 & -0.042 \\
\hline
\end{tabular}

$\dagger$ Age adjusted death rate calculated based on a 1985 model population. $\ddagger$ Per capita amount of income generated by residents, businesses, and other entities that reside or exist in a prefecture. \$Per capita net amount of money transferred from a prefecture to the national coffers. ${ }^{\star} \mathrm{p}<0.05$. Okinawa in 1965 and 1970 and Hyogo in 1995 were excluded for calculation.

in 1990 and 1995. The table clearly shows the statistical significance level of the correlation coefficients and the trend of the coefficients. Prefectures that largely depend on outside financial sources experienced higher death rates than those that were not dependent in that way. The correlation between the per capita prefectural contribution and the age adjusted death rate was negative and statistically significant from 1965 through 1975. The correlation continued to be negative but not statistically significant in 1980 and later years. The correlation coefficients between the female age adjusted death rate and per capita prefectural income in 1990 and 1995 were 0.270 and 0.204 , respectively; that between the female age adjusted death rate and per capita prefectural contribution were 0.286 and 0.0265 in 1990 and 1995, respectively.

\section{Discussion}

This study showed that the national financial adjustment policy balanced the revenues of local governments by allocating, in the form of local allocation taxes and treasury disbursements, national taxes collected from economically productive prefectures to economically less productive prefectures. We concluded that this policy has served to increase the health levels of rural prefectures and, as a result, to equalise the health levels of prefectures throughout the country. However, this policy has manifested difficulties in responding to the megacity health issues that have been present in the nation's capital city.

The national financial adjustment policy has been reallocating taxes collected from communities that are relatively more successful economically to communities of weaker economic condition. The results of the prefectural financial indicators clearly demonstrated that the equivalent of 0.41 to 0.76 of the annual total amount of national taxes collected has been allocated to local governments as local allocation taxes or treasury disbursements during the period from 1965 through 1995. The significant tight correlations shown between the per capita prefectural income and financial contribution by prefectures during 1965-75 indicated that economically productive prefectures are financially much contributing to the less productive prefectures. This policy might have encouraged developing health supportive conditions in prefectures with inadequate economy.

Local governments have been committed to providing the infrastructure and services that support health. National fiscal statistics showed that the share of local governments' versus national government's role within public sector is large: local governments spending were accounted for more than $80 \%$ of all government expenditure on health promotion, education, and continuing education; for between $65 \%$ and $80 \%$ of all government expenditure on urban planning, road construction, water supply, sewage management, development of local business and industry, housing, and social welfare. ${ }^{18}$ Regarding the public versus private shares of local level expenditures on health supporting services, Mundle reported that in Japan in $199173 \%$ was financed by the public sector. ${ }^{8}$ It was regarded that the role of local governments in preparing health supportive infrastructural development and health related services is large, however the local governments' own financial basis to continuously fully fund such locally operated programmes is not sufficient.

The national financial adjustment system has financially enabled local governments to provide infrastructures and social services for health in the local communities. It is generally known that local allocation taxes have been used for any of the account of expenditures and treasury disbursements have individual specific purposes such as infrastructural development, compulsory education, welfare assistance, and child welfare assistance. ${ }^{16}$ As of 1995 , local allocation taxes and treasury disbursements supplied $15.1 \%$ and $14.0 \%$ of the local government revenue respectively. ${ }^{16}$ The proportion of the supply from the national government to the revenue of the local municipal governments with small size population was greater than that of the local municipal governments with large size population. ${ }^{18}$ These reviews of the specific accounts of treasury disbursements and general accounts of local government's expenditure showed us that health infrastructures have been developed not by direct operations by the national government but by the local governments' operations with the financial support from the national government to the local governments. The amount of financial support has been greater for the local governments with fewer own local revenue sources.

The national financial adjustment system was thought to have enabled rural governments that have relatively small amounts of revenues of their own to invest in social overhead capital and social services, and this has contributed to improving the health of rural populations during the recent three decades in Japan. Differences in sewage coverage rates and percentage of paved roads among prefectures has been 
diminished. ${ }^{18}$ Per capita medical care resources and welfare service providing facilities are greater in some rural communities than in the urban communities. ${ }^{19} 20$ Disease preventive social services to provide health check ups for community members have been equally provided at the local level regardless of their own financial capacity. ${ }^{21}$ It is understood that preparation of sufficient health supportive infrastructure and appropriate social services contribute to promote health of the population. ${ }^{22}$ Considering the installation of these health infrastructures and services in rural prefectures and their contribution to population health gain, it could be regarded as the adjustment policy contributed to equalise health level by prefectures across the nation.

As it is generally known that the health level and economic level indicators of governing units have positive correlations among countries, ${ }^{2324}$ and among areas in a country, ${ }^{25}$ a significant association between improved economic situations and improved health conditions existed from 1965 until 1975. However, this relation became relatively weak in the 1980 s and was not observed in the 1990s. It is noteworthy that the clear relation that had existed between economic levels and health levels has disappeared. Along with this change in the relation between health and economic conditions, the size of the disparity of health levels among prefectures throughout the country had diminished by 1995 . A more equal distribution of health levels among prefectures has been achieved, and the income level variation among prefectures within Japan has become not associated with the health level variation. We have regarded that the national financial adjustment policy had worked to reduce pre-existing inequities in health throughout the country.

Concerning the relation of prefectures in the national adjustment system, the contribution of Tokyo to other local governments - as shown by the per capita prefectural financial contribution of Tokyo-has consistently been the largest. It has differed the greatest by far from both the national average and the amount contributed by the prefecture that contributed the second highest amount. Even excluding the tax collected from businesses, Tokyo's contribution has been consistently distinctive. This relatively larger reliance on Tokyo continued even after the collapse of the bubble economy and the Asian economic crisis. The Tokyo government has never received any local allocation tax money since this system was introduced in 1953; since 1993 Tokyo is the only prefectural government not receiving such funds. ${ }^{16}$ These facts indicate that a large amount of national taxes collected from people in Tokyo has been reallocated to other areas of the country through the central government. In relation to this condition, there are number of issues Tokyo faces. Tokyo is still struggling with the negative economic conditions, and is facing number of issues relating to employment: a continuing decline in the ratio of job offers to job seekers; a higher unemployment rate in the greater Tokyo area than across Japan as a
KEY POINTS

- The national financial adjustment system has provided local governments with support; the largest annual amount was 31116 billion yen in 1995 .

- Differences in the age adjusted death rates among prefectures diminished from 1965 through 1995.

- Higher prefectural incomes and lower mortality rates were positively correlated from 1965 until 1975, but the correlation became indistinct after 1980 .

- The national financial adjustment policy has helped to reduce disparities in health levels across Japan.

- The relative health level of the nation's capital city has consistently declined during the period of this study, falling below the national average.

whole; and employment of one fourth of the city's workers at small size establishments having less than 20 employees or at service companies having less than five employees. ${ }^{26}$ Other issues that Tokyo has been facing include: a superannuated urban infrastructure that needs to be refurbished; an extremely high density population; housing costs that are 1.6 times higher than the national average; heavy vehicular traffic; air, water, and soil pollution resulting from such traffic, as well as from industrial activities, rubbish, and other causes; and problems relating to the collection and treatment of rubbish. ${ }^{27}$

Along with this situation, the present results clearly showed relative decline of Tokyo's health level. A significant decrease in the relative size of the reduction of the age adjusted death rate of Tokyo by 10 years suggests a further relative decline in Tokyo's health level. If one considers the accumulation of megacity issues that probably will negatively affect the health of this city's residents, a further decrease in the relative health of Tokyo is a matter for concern. Considering the large contribution by Tokyo to other prefectures through the national financial adjustment system along with the accumulation of megacity issues affecting health in Tokyo, it could be regarded that the national financial adjustment policy has increased the health levels of rural prefectures but has resulted in the relative decline of the health level of Tokyo. Even if Tokyo enjoys high economic productivity, it must retain the taxes that it collects in order to be able to redevelop its social overhead capital and to provide particular social services so as to prevent any further decline in its health levels. Accordingly, new financial policies in addition to the aforementioned national financial adjustment policy are now required to meet this megacity's arising needs for infrastructural investments and the provision of health promoting services for its residents.

In conclusion, the national financial adjustment policy to balance the revenues of local governments has increased the health levels of rural prefectures, and it is probable that the 
policy has worked to equalise the health levels of prefectures throughout the country. However, the policy has precluded the nation's capital city from applying its economic resources as local government expenditures to deal with the urban issues affecting health that such a megacity faces. We are concerned that if appropriate policies are not adopted and implemented, the relative health level of Tokyo will decline further.

Funding: this research is partly supported by a Grant in Aid of Scientific Research by the Japan Society of Promotion of Science.

Conflicts of interest: none.

POLICY IMPLICATIONS

- The central government should consider moderating of the overly effective mechanism that siphons economic gains from Tokyo and impedes health promotion for Tokyo citizens.

- A better utilisation of the benefits of accumulation of economic activities could contribute to the health of Tokyo's citizens through the introduction by the Tokyo government of a local tax earmarked for investment in health infrastructure and activities.

- The earmarked tax collected in Tokyo should be reallocated to municipalities within Tokyo, with scarce resources, to develop infrastructure for health promotion and to reduce disparities of health levels among municipalities of Tokyo.

TAKEHITO TAKANO KEIKO NAKAMURA

Health Promotion/International Health, Division of Public Health, Graduate School, Tokyo Medical and Dental University, Fapan

1 Sugimoto K, ed. Finance of Japan, Fiscal Year 1999. Tokyo: Toyo Keizai Shinposha, 1999

2 Hayashi Y, ed. Local finance. Tokyo: Yuhikaku, 1999.

3 Study Group on the Local Allocation Tax System. Introduction to the Local Allocation Tax. Tokyo: Gyousei, 1999.
4 Detels R, Breslow L. Current scope. In: Holland Ww, Detels R, Knox G, eds. Oxford textbook of public health. Vol 1: History, determinants, scope and strategies. Oxford: Oxford History, determinants, scope and

5 Lawrence RJ. Wanted: designs for health in the urban environment. World Health Forum, 1996;17:363-86.

6 Division of Health Promotion, Education and Communication, World Health Organization. Health promotion glossary. Geneva: WHO, 1998.

7 Marmott M, Wilkinson R, eds. Social determinants of health. Oxford: Oxford University Press, 1999.

8 Mundle S. Financing human development: some lessons from advanced Asian countries. World Development 1998; 26:659-72.

9 Health and Welfare Statistics Association. Tokyo: Health and Welfare Statistics Association, 1997.

10 Taniguchi R, Hoshi T, Fujiwara Y. Trends concerning life expectancy by prefectures: characteristics of the life expectancy of Tokyo citizens. Kousei-no-sihyo 1999;46:24-31.

11 Takano T. Accumulation of ill health in the Shita-machi area of Tokyo. Minzokueisei 1998;64:5-25.

12 Economic Research Institute Economic Planning Agency. Annual report on prefectural accounts. Tokyo: Printing Office of the Ministry of Finance, 1974 and 1998.

13 Statistics Bureau, Management and Coordination Agency. Population census of fapan. Tokyo: Statistics Bureau, Management and Coordination Agency, 1968, 1973, 1978, 1983, 1988, 1993, and 1998.

14 Economic Research Institute Economic Planning Agency. Annual report of national accounts. Tokyo: Printing Office of the Ministry of Finance, 1986 and 2000.

15 National Tax Agency. Annual statistical report concerning the national tax administration. Tokyo: Okura Zaimu Kyoukai. 1965, 1970, 1975, 1980, 1985, 1990, and 1995.

16 Institute of Local Finance. Annual statistical report concerning local finance. Tokyo: Association of Local Finance, 1967, 1972, 1977, 1982, 1987, 1992, and 1997.

17 Statistics and Information Division, Minister's Office, Ministry of Health and Welfare. Trends concerning age-adjusted death rates by prefectures. Tokyo: Ministry of Health and death rates by

18 Ministry of Home Affairs. White paper on local finance, 2000. Tokyo: Ministry of Home Affairs, 2000

19 Ministry of Health and Welfare. Survey concerning medical care facilities, 1997. Tokyo: Health and Welfare Statistics Association, 1999

20 Nihon Keizai Shinbun/Nikkei Research Institute of Industry and Markets. Gyousei Kaikaku: Kensyo-Gyousei Service no Minkatsu Dounyu. [In Japanese]. Tokyo: Nihon Keizai Shinbun, 1998.

21 Health and Welfare Bureau for the Elderly, Ministry of Health and Welfare. Map of health in municipalities. Tokyo: Japan Health Promotion and Fitness Foundation, 2000

22 Takano T, Nakamura K. An analysis of health levels and various indicators of urban environments for Healthy Cities projects. F Epidemiol Community Health 2001;55:263-70. orld Bank. World Development Report 1993: Investing in health. New York: Oxford University Press, 1993.

24 Mackenbach JP, Kunst AE, Cavelaars AE, et al. Socioeconomic inequalities in morbidity and mortality in western Europe. The EU Working Group on Socioeconomic Inequalities in Health. Lancet 1997;349:1655-9.

25 Rodriguez JA, Lemkow L. Health and social inequities in Spain. Soc Sci Med 1990;31:351-8.

26 Bureau of Labor and Economic Affairs, Tokyo Metropolitan Government. Industry and labor in Tokyo 2000. Tokyo: Tokyo Metropolitan Government, 2000.

27 Bureau of City Planning, Tokyo Metropolitan Government. Urban white paper of Tokyo Metropolis 2000. Tokyo: Tokyo Metropolitan Government, 2000. 